\title{
Prognostic significance of CD168 overexpression in colorectal cancer
}

\author{
$\mathrm{KE} \mathrm{WANG}^{1}$ and TAO $\mathrm{ZHANG}^{2}$ \\ ${ }^{1}$ Department of Oncology, Cancer Institute; ${ }^{2}$ Department of Preventive and Health Care, \\ Second Affiliated Hospital, Zhejiang University School of Medicine, Hangzhou, Zhejiang 310009, P.R. China
}

Received April 5, 2015; Accepted May 26, 2016

DOI: $10.3892 /$ ol.2016.4974

\begin{abstract}
The expression of cluster of differentiation 168 (CD168), a cell surface receptor for hyaluronan, is associated with cancer progression and metastases. The aim of the present study was to analyze the expression of CD168 by immunohistochemistry in colorectal cancer (CRC) and to examine the association between CD168 expression and clinicopathological features, including survival. A total of 78 tissue specimens obtained from consecutive CRC patients exhibiting various tumor node metastasis (TNM) stages were immunostained for the analysis of CD168 expression. The prognostic value of CD168 was subsequently evaluated. Kaplan-Meier survival analysis revealed that CD168 overexpression was significantly associated with overall survival $(\mathrm{P}<0.05)$; however, no significant association was identified between CD168 expression and tumor location, tumor differentiation or TNM stage. Overexpression of CD168 was closely associated with poorer patient survival, which indicates that it may present a useful indicator for clinical prognosis.
\end{abstract}

\section{Introduction}

Cluster of differentiation 168 (CD168), also known as receptor for hyaluronan mediated motility, is a hyaluronan (HA)-binding protein, which is expressed in various tumors, including breast, gastric, prostate and colorectal cancer (CRC) (1-4). CD168 was originally identified as a HA-dependent motility cell surface receptor, which transforms fibroblasts when overexpressed (5). CD168 has been identified in cytoplasmic and nuclear compartments where it interacts with interphase microtubules and centrosomes and regulates the tumor suppressor gene, breast cancer 1 (6). In addition, a previous study demonstrated that CD168 activates downstream signaling, such as Rho GTPase kinase cascades,

Correspondence to: Dr Tao Zhang, Department of Preventive and Health Care, Second Affiliated Hospital, Zhejiang University School of Medicine, 88 Jiefang Road, Hangzhou, Zhejiang 310009, P.R. China E-mail: zzzhangtao06@126.com

Key words: cluster of differentiation 168, immunohistochemistry, prognosis, colorectal cancer and increases cellular motility (7). Notably, CD168 is often upregulated in multiple cancers and has subsequently been linked to cancer progression $(8,9)$. Clinically, the accumulation of HA within the cancer or peritumor stroma has been identified as a marker of poor prognosis in breast cancer patients (10). In addition, Ishigami et al (11) revealed that the expression of CD168 was significantly associated with biological aggressiveness in gastric cancer (11). Therefore, it is important to validate the function of CD168 in clinical samples. This presents a critical step toward the development of effective therapeutic intervention. Therefore, the present study investigated the clinical features of CD168 expression and analyzed the association between CD168 expression and the clinical outcome of CRC patients following surgical resection.

\section{Materials and methods}

Patients and specimens. A total of 78 consecutive patients with primary colorectal adenocarcinomas (stage I-IV) who underwent curative surgical resection at The Second Affiliated Hospital (Hangzhou, China) between January 2006 and November 2012, with data available for study in the archives of the Department of Pathology, were included in the study. All patients were followed-up for $\geq 5$ years or until mortality. All histopathological information was systematically re-reviewed from the corresponding hematoxylin and eosin stained tissues, including tumor-node-metastasis (TNM) classification, tumor grade and histological subtype, according to the American Joint Committee on Cancer staging system (12). Clinical information was obtained from patient records and included age, gender, tumor location and survival time. The pathological and clinical information of the patients is summarized in Table I. The present study was approved by the Research Ethics Board at Zhejiang University (Hangzhou, Zhejiang, China).

Tissue microarray (TMA). A TMA was assembled using tissues obtained from 78 primary CRC patients according to the following procedure. Briefly, the TMA was assembled using a needle to obtain a donor core from morphologically representative areas of donor tissue blocks and mounted into the recipient paraffin block using a custom-made precision instrument (Beecher Instruments, Inc., Sun Prairie, WI, USA). TMA sections (0.6-mm thick) were cut and placed onto slides using standard techniques (13). 
Table I. Clinicopathological data of the 78 colorectal cancer patients included in the present study.

\begin{tabular}{lc}
\hline Clinicopathological parameter & Patient, $\mathrm{n}(\%)$ \\
\hline Gender & \\
Male & $52(66.7)$ \\
Female & $26(33.3)$ \\
Age, years & \\
$<65$ & $41(52.6)$ \\
$\geq 65$ & $37(47.4)$ \\
Tumor location & \\
Colon & $38(48.7)$ \\
Rectum & $40(51.3)$ \\
Histological differentiation & \\
Well-differentiated & $26(33.3)$ \\
Moderately-differentiated & $36(46.2)$ \\
Poorly-differentiated & $16(20.5)$ \\
Tumor stage & \\
T1 & $1(1.3)$ \\
T2 & $7(9.0)$ \\
T3 & $30(38.5)$ \\
T4 & $40(51.3)$ \\
Lymph node involvement & \\
N0 & $42(53.8)$ \\
N1 & $24(30.8)$ \\
N2 & $12(15.4)$ \\
Metastasis & \\
M0 & $73(93.6)$ \\
M1 & $5(6.4)$ \\
TNM stage & \\
I & $5(6.4)$ \\
II & $37(47.4)$ \\
III & $31(39.7)$ \\
IV & $5(6.4)$ \\
& \\
& \\
&
\end{tabular}

${ }^{a}$ American Joint Committee on Cancer staging system. TNM, tumor-node-metastasis.

Immunohistochemical staining. The expression of CD168 in $\mathrm{CRC}$ tissues was evaluated according to the following procedure. Antigen retrieval was performed in phosphate-buffered saline (PBS) with $3 \%$ citrate buffer at $120^{\circ} \mathrm{C}$ for $10 \mathrm{~min}$. Slides were then cooled at room temperature (RT) for $10 \mathrm{~min}$, rinsed in PBS buffer solution and placed in the Autostainer Link 48 (Dako, Glostrup, Denmark) for staining. Rabbit monoclonal CD168 antibody (catalog no. EPR4055; Epitomics, Burlingame, CA, USA), diluted to 1:100 with PBS, was applied and incubation was performed for $30 \mathrm{~min}$ at RT. Tumor tissues were then visualized using the avidin biotinylated peroxidase method (14), in accordance with the manufacturer's instructions (Jinqiao Biological Technology Co., Beijing, China). Sections were then treated with streptavidin-peroxidase complex. Cases previously known to be positive were used as positive controls (MCF-7 cell lysate paraffin-embedded breast
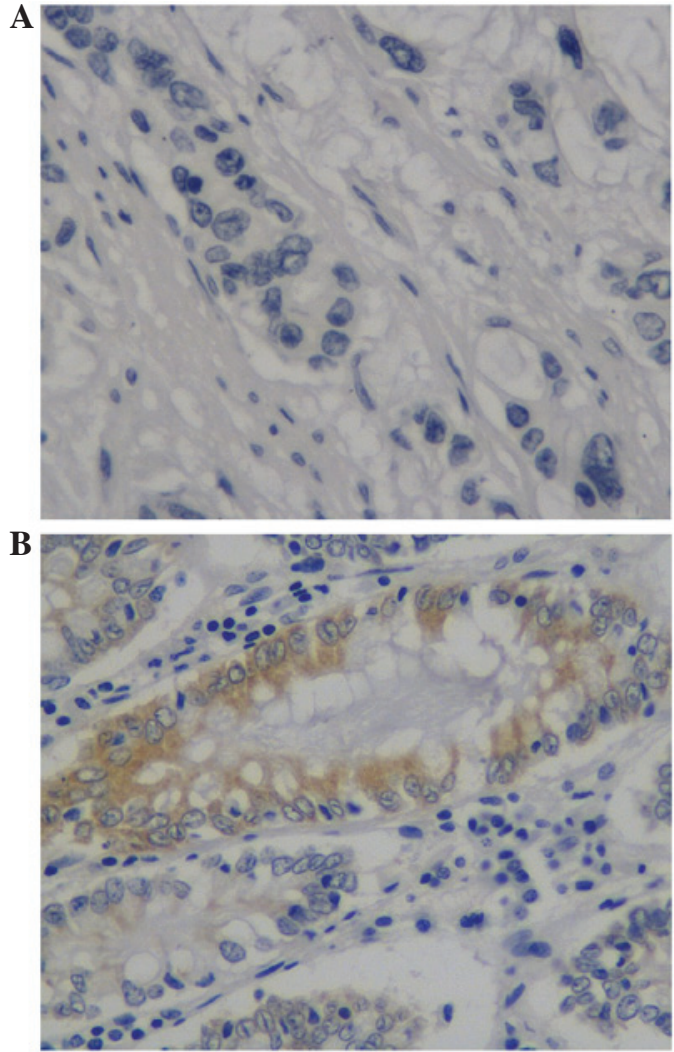

Figure 1. Representative images of (A) negative and (B) intense positive CD168 expression in tissue microarrays of colorectal cancer. $\mathrm{x} 40$ magnification.

carcinoma tissues; MCF-7 cells were purchased from the Cell Bank of the Chinese Academy of Medical Science, Beijing, China). Cell-infiltrating cancer in stained sections was used as a negative control.

Evaluation of CD168 protein expression. CD168 expression in CRC was analyzed, as described previously (15). Briefly, the intensity of immunohistochemical staining was evaluated by two independent pathologists, who were blinded to the clinical data and disease outcome. In cases of discrepant assessments, the sections were evaluated using a double-headed microscope and staining was discussed until an agreement was reached. CD168 staining was classified into three categories: 0 , no staining; 1 , weak membranous and cytoplasmic expression in $>10 \%$ of cancer cells; 2 , weak to moderate expression in $>10 \%$ of the cancer cells; and 3, strong expression in $>10 \%$ of the cancer cells. The association between clinicopathological factors and CD168 expression was then investigated.

Statistical analysis. Statistical analysis was performed using GraphPad Prism 5.0 software (GraphPad Software, Inc., La Jolla, CA, USA). Clinicopathological factors were evaluated using the $\chi^{2}$ test and Fisher's exact test was used to assess the significance between categorical variables. Survival curves of positive or negative CD168 overexpression groups were generated using the Kaplan-Meier method and statistical significance was determined by log-rank test. Cox regression analysis was used for multivariate analysis of independent prognostic factors for survival. $\mathrm{P}<0.05$ was considered to indicate a statistically significant difference. 
Table II. Correlation between CD168 OE and clinicopathological parameters of 78 colorectal patients.

\begin{tabular}{|c|c|c|c|}
\hline \multirow[b]{2}{*}{ Parameter } & \multicolumn{2}{|c|}{ CD168 OE } & \multirow[b]{2}{*}{ P-value } \\
\hline & $(-), \mathrm{n}$ & $(+), \mathrm{n}$ & \\
\hline Gender & & & 0.04 \\
\hline Male & 46 & 6 & \\
\hline Female & 18 & 8 & \\
\hline Age, years & & & 0.62 \\
\hline$<65$ & 34 & 7 & \\
\hline$\geq 65$ & 29 & 8 & \\
\hline Tumor location & & & 0.20 \\
\hline Colon & 29 & 9 & \\
\hline Rectum & 35 & 5 & \\
\hline Histological differentiation & & & $0.41^{\mathrm{a}}$ \\
\hline Well-differentiated & 25 & 1 & \\
\hline Moderately-differentiated & 27 & 9 & \\
\hline Poorly-differentiated & 12 & 4 & \\
\hline Tumor stage & & & $0.67^{\mathrm{b}}$ \\
\hline $\mathrm{T} 1$ & 1 & 0 & \\
\hline $\mathrm{T} 2$ & 6 & 1 & \\
\hline $\mathrm{T} 3$ & 24 & 6 & \\
\hline $\mathrm{T} 4$ & 33 & 7 & \\
\hline Lymph node involvement & & & $0.78^{\mathrm{c}}$ \\
\hline No & 34 & 8 & \\
\hline N1 & 22 & 2 & \\
\hline $\mathrm{N} 2$ & 8 & 4 & \\
\hline Metastasis & & & 0.23 \\
\hline M0 & 60 & 13 & \\
\hline M1 & 4 & 1 & \\
\hline TNM stage $^{d}$ & & & $0.78^{\mathrm{e}}$ \\
\hline I & 4 & 1 & \\
\hline II & 30 & 7 & \\
\hline III & 26 & 5 & \\
\hline IV & 4 & 1 & \\
\hline
\end{tabular}

${ }^{a}$ Well- and moderately-differentiated vs. poorly-differentiated. ${ }^{\mathrm{b}} \mathrm{T} 1+\mathrm{T} 2$ vs. T3+T4. ${ }^{\mathrm{c}} \mathrm{N} 0$ vs. $\mathrm{N} 1+\mathrm{N} 2 .{ }^{\mathrm{da}}$ American Joint Committee on Cancer staging system. ${ }^{\mathrm{e}} \mathrm{I}+\mathrm{II}$ vs. III+IV. (-), negative overexpression; $(+)$, positive overexpression; CD168, cluster of differentiation 168; OE, overexpression; TNM, tumor-node-metastasis.

\section{Results}

CD168 expression in CRC tissues. CD168 expression was identified on the cell membrane and in the cytoplasm (Fig. 1). Of the 78 patients, $72(92.3 \%)$ cases exhibited positive membrane or cytoplasmic CD168 expression, whereas $6(7.7 \%)$ cases exhibited negative CD168 expression. Subsequently, the patients were divided into two groups according to CD168 expression: i) CD168 overexpression negative group (patients exhibiting no, weak and moderate staining of tumor cells in the entire cancer area; and ii) CD168 overexpression positive group (staining intensity $>2$ ). Normal colonic epithelium exhibited no expression of CD168.
$\mathbf{A}$
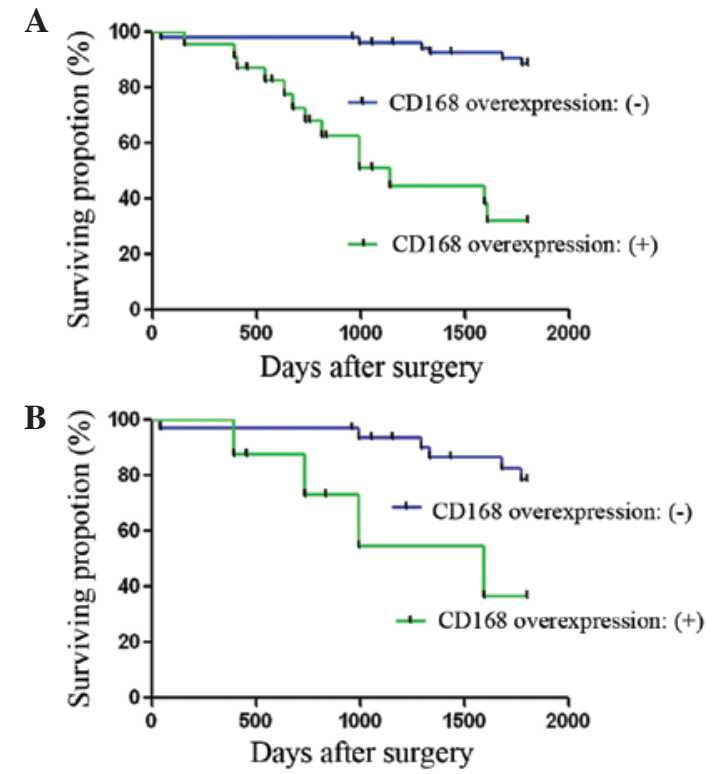

(I+II)

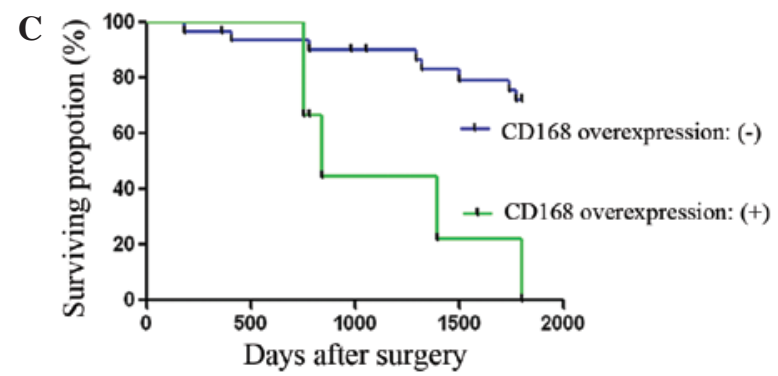

(III+IV)

Figure 2. Kaplan-Meier survival analysis of colorectal cancer (CRC) patients negative or positive for CD168 overexpression. CD168 overexpression was associated with shorter overall survival times. Analysis of (A) all patients, (B) patients with stage I+II CRC and (C) patients with stage III+IV CRC.

Association between CD168 overexpression and clinicopathological features. Clinicopathological analysis revealed that CD168 overexpression was more common in female patients than male patients $(\mathrm{P}=0.04)$ (Table II). However, no statistically significant associations were identified between CD168 overexpression and other clinicopathological features, including age, tumor size, tumor location, histology and TNM classification.

Association between CD168 overexpression and overall survival of CRC patients. The 5-year survival rates of the CD168 overexpression negative and positive groups were 83.3 and $40 \%$, respectively. The association between CD168 overexpression and overall survival in colorectal adenocarcinoma patients was analyzed using Kaplan-Meier analysis. Patients of the CD168 overexpression positive group exhibited significantly worse survival than that of CD168 overexpression negative group ( $\mathrm{P}=0.002)$ (Fig. 2). Multivariate Cox regression analysis revealed that $\mathrm{CD} 168$ overexpression was a negative prognostic factor for the CD168 overexpression positive group when compared with that of the CD168 overexpression negative group $(\mathrm{P}<0.05)$.

These data indicate that CD168 expression is an independent adverse survival factor in CRC. 


\section{Discussion}

A number of studies have indicated that CD168 expression is significantly associated with high metastatic potential or cancer progression in multiple myeloma, gastric, breast and pancreatic cancers $(11,16-18)$. In the present study, the results indicate that overexpression of the CD168 protein leads to reduced overall survival and is an independent adverse survival factor in CRC. In accordance with the results of the present study, Zlobec et al (19) reported that the combined immunohistochemical profile of CD168/tumor infiltrating lymphocytes could identify patients with an adverse prognosis. However, the study investigated the clinical impact of CD168 expression in rectal cancer, and did not include CRC. Therefore, further investigation is required to elucidate the association between CD168 expression and clinical factors in CRC.

CD168 is an $85 \mathrm{kDa}$ multifunctional protein that is often upregulated in advanced malignancies. It is involved in cell motility and signaling, as well as oncogenic events. CD168 exists in several variant forms and may be expressed at the cell surface and intracellularly, where it exhibits different functions $(20,21)$. When expressed at the cell surface, CD168 acts as a receptor for $\mathrm{HA}$, which has been implicated in cancer cell invasiveness (22). A previous study demonstrated that CD168 binds to HA and modulates microtubule-associated protein interactions with actin (23). Yamada et al (24) reported that increased mRNA expression of CD168 at various stages of $\mathrm{CRC}$ was associated with cancer progression. Furthermore, Zlobec et al (25) suggested that CD168 expression is an important contributor to CRC cell migration and dispersal, regardless of whether tumors were lymph node-positive or negative. These data are consistent with the results of the present study.

Immunohistochemical analysis in the present study indicates that CD168 overexpression is not associated with common clinical parameters of CRC, such as tumor location, tumor differentiation or TNM stage. However, high CD168 expression was an important prognostic factor in patients with CRC. Considering the function of CD168 as a receptor and its involvement in the Ras/mitogen-activated protein kinase signaling pathway $(14,26)$, CD168 may present a potential candidate for therapeutic intervention. Therefore, further studies of CD168 and its potential as a marker for CRC prognosis in the clinic are required.

\section{Acknowledgements}

The present study was supported by The National Natural Science Foundation of China (grant no. 81401934) and The Natural Science Foundation of Zhejiang Province (grant no. LY14H160021).

\section{References}

1. Assmann V, Marshall JF, Fieber C, Hofmann M and Hart IR: The human hyaluronan receptor RHAMM is expressed as an intracellular protein in breast cancer cells. J Cell Sci 111: 1685-1694, 1998.

2. Li H, Guo L, Li J, Liu N and Liu J: Alternative splicing of RHAMM gene in chinese gastric cancers and its in vitro regulation. Zhonghua Yi Xue Yi Chuan Xue Za Zhi 17: 343-347, 2000 (In Chinese).
3. Lin SL, Chang D, Chiang A and Ying SY: Androgen receptor regulates CD168 expression and signaling in prostate cancer. Carcinogenesis 29: 282-290, 2008.

4. Zlobec I, Steele R, Terracciano L, Jass JR and Lugli A: Selecting immunohistochemical cut-off scores for novel biomarkers of progression and survival in colorectal cancer. J Clin Pathol 60: 1112-1116, 2007.

5. Yang B, Zhang L and Turley EA: Identification of two hyaluronan-binding domains in the hyaluronan receptor RHAMM. J Biol Chem 268: 8617-8623, 1993.

6. Maxwell CA, Benitez J, Gomez-Baldó L, Osorio A, Bonifaci N, Fernández-Ramires R, Costes SV, Guinó E, Chen H, Evans GJ, et al: Interplay between BRCA1 and RHAMM regulates epithelial apicobasal polarization and may influence risk of breast cancer. PLoS Biol 9: e1001199, 2011.

7. Gouëffic Y, Guilluy C, Guérin P, Patra P, Pacaud P and Loirand G: Hyaluronan induces vascular smooth muscle cell migration through RHAMM-mediated PI3K-dependent Rac activation. Cardiovasc Res 72: 339-348, 2006.

8. Hamilton SR, Fard SF, Paiwand FF, Tolg C, Veiseh M, Wang C, McCarthy JB, Bissell MJ, Koropatnick $J$ and Turley EA: The hyaluronan receptors CD44 and Rhamm (CD168) form complexes with ERK1,2 that sustain high basal motility in breast cancer cells. J Biol Chem 282: 16667-16680, 2007.

9. Hall CL, Wang C, Lange LA and Turley EA: Hyaluronan and the hyaluronan receptor RHAMM promote focal adhesion turnover and transient tyrosine kinase activity. J Cell Biol 126: 575-588, 1994.

10. Auvinen P,Tammi R,Kosma VM,Sironen R, Soini Y,Mannermaa A, Tumelius R, Uljas E and Tammi M: Increased hyaluronan content and stromal cell CD44 associate with HER2 positivity and poor prognosis in human breast cancer. Int J Cancer 132: 531-539, 2013.

11. Ishigami S, Ueno S, Nishizono Y, Matsumoto M, Kurahara $\mathrm{H}$, Arigami T, Uchikado Y, Setoyama T, Arima H, Yoshiaki K, et al: Prognostic impact of CD168 expression in gastric cancer. BMC Cancer 11: 106, 2011.

12. Lee SA, Kwon HC, Park MA, Jung CK, Kim SH, Park KJ, Choi HJ, Lee HS, Roh MS and Kim JS: Impact of the new AJCC staging system and adjuvant treatment in rectal cancer. Cancer Res Treat 36: 121-127, 2004.

13. Hilska M, Roberts PJ, Collan YU, Laine VJ, Kossi J, Hirsimaki P, Rahkonen $\mathrm{O}$ and Laato M: Prognostic significance of matrix metalloproteinases-1, $-2,-7$ and -13 and tissue inhibitors of metalloproteinases-1, $-2,-3$ and -4 in colorectal cancer. Int J Cancer 121: 714-723, 2007.

14. Hsu SM, Raine L and Fanger H: Use of avidin-biotin-peroxidase complex $(\mathrm{ABC})$ in immunoperoxidase techniques: a comparison between ABC and unlabeled antibody (PAP) procedures. J Histochem Cy tochem 29: 577-580, 1981.

15. Lin SL, Chang D, Chiang A and Ying SY: Androgen receptor regulates CD168 expression and signaling in prostate cancer. Carcinogenesis 29: 282-290, 2008.

16. Maxwell CA, Rasmussen E, Zhan F, Keats JJ, Adamia S, Strachan E, Crainie M, Walker R, Belch AR, Pilarski LM, et al: RHAMM expression and isoform balance predict aggressive disease and poor survival in multiple myeloma. Blood 104: 1151-1158, 2004.

17. Abetamann V, Kern HF and Elsässer HP: Differential expression of the hyaluronan receptors CD44 and RHAMM in human pancreatic cancer cells. Clin Cancer Res 2: 1607-1618, 1996.

18. Wang C, Thor AD, Moore DH II, Zhao Y, Kerschmann R, Stern R, Watson PH and Turley EA: The overexpression of RHAMM, a hyaluronan-binding protein that regulates ras signaling, correlates with overexpression of mitogen-activated protein kinase and is a significant parameter in breast cancer progression. Clin Cancer Res 4: 567-576, 1998.

19. Zlobec I, Baker K, Terracciano L, Peter S, Degen L, Beglinger C and Lugli A: Two-marker protein profile predicts poor prognosis in patients with early rectal cancer. Br J Cancer 99: 1712-1717, 2008.

20. Turner RR, Li C and Compton CC: Newer pathologic assessment techniques for colorectal carcinoma. Clin Cancer Res 13 (Suppl): S6871-S6876, 2007.

21. Samuel SK, Hurta RA, Spearman MA, Wright JA, Turley EA and Greenberg AH: TGF-beta 1 stimulation of cell locomotion utilizes the hyaluronan receptor RHAMM and hyaluronan. J Cell Biol 123: 749-758, 1993.

22. Akiyama Y, Jung S, Salhia B, Lee S, Hubbard S, Taylor M, Mainprize T, Akaishi K, van Furth W and Rutka JT: Hyaluronate receptors mediating glioma cell migration and proliferation. J Neurooncol 53: 115-127, 2001. 
23. Shigeishi H, Fujimoto S, Hiraoka M, Ono S, Taki M, Ohta K, Higashikawa $\mathrm{K}$ and Kamata $\mathrm{N}$ : Overexpression of the receptor for hyaluronan-mediated motility, correlates with expression of microtubule-associated protein in human oral squamous cell carcinomas. Int J Oncol 34: 1565-1571, 2009.

24. Yamada Y, Itano N, Narimatsu H, Kudo T, Hirohashi S, Ochiai A Niimi A, Ueda M and Kimata K: Receptor for hyaluronan-mediated motility and CD44 expressions in colon cancer assessed by quantitative analysis using real-time reverse transcriptase-polymerase chain reaction. Jpn J Cancer Res 90: 987-992, 1999.
25. Zlobec I, Baker K, Terracciano LM and Lugli A: RHAMM, p21 combined phenotype identifies microsatellite instability-high colorectal cancers with a highly adverse prognosis. Clin Cancer Res 14: 3798-3806, 2008.

26. Zhang S, Chang MC, Zylka D, Turley S, Harrison R and Turley EA: The hyaluronan receptor RHAMM regulates extracellular-regulated kinase. J Biol Chem 273: 11342-11348, 1998. 